\title{
A história da geografia cultural e o conceito de paisagem
}

\author{
The history of cultural geography and the concept of landscape
}

Felipe da Silva Vieira

Mestrando em Geografia pelo Programa de Pós-graduação em Geografia da UNIFAL-MG, integrante do Grupo de Estudos Regionais e Socioespaciais (GERES) da UNIFAL-MG, Brasil felipe.vieira@sou.unifal-mg.edu.br

Flamarion Dutra Alves

Doutor em Geografia pela UNESP - Rio Claro e Professor Associado II do Programa de Pósgraduação em Geografia da UNIFAL-MG e Programa de Pós-graduação em Geografia da UFSJ, Líder Do Grupo de Estudos Regionais e Socioespaciais (GERES) da UNIFAL-MG, Brasil flamarion.dutra@unifal-mg.edu.br

Jhonatan da Silva Corrêa

Mestrando em Geografia pelo Programa de Pós-graduação em Geografia da UNIFAL-MG, bolsista Capes, integrante do Grupo de Estudos Regionais e Socioespaciais (GERES) da UNIFAL-MG e Núcleo de Estudos e Pesquisa Sobre Espaço e Cultura (NEPEC) em rede da UERJ, Brasil jhonatan.correa@sou.unifal-mg.edu.br

Tamyris Maria Moreira da Costa Mestranda em Geografia pelo Programa de Pós-graduação em Geografia da UNIFAL-MG, bolsista Capes e integrante do Grupo de Estudos Regionais e Socioespaciais (GERES) da UNIFAL-MG, Brasil tamyris.costa@sou.unifal-mg.edu.br

\begin{abstract}
Resumo
O desenvolvimento da geografia como ciência se consolida no século $\mathrm{XX}$, como uma forma de interpretação da sociedade em suas várias dimensões. Entre elas, destaca-se a dimensão cultural, que foi ganhando importância e alterando suas bases conceituais e metodológicas. Nesse sentido, o objetivo do artigo é realizar uma revisão bibliográfica sobre a geografia cultural, trazendo reflexões sobre seu papel dentro da ciência geográfica, com o intuito de mostrar as principais ideias, características e transformações. Para isso, investiga-se também o conceito de paisagem, que está associado à geografia cultural desde seu surgimento. Assim, a geografia tradicional dará ênfase a uma perspectiva material e descritiva da cultura na paisagem, e a partir da segunda metade do século XX, a nova geografia cultural agregará elementos simbólicos, imateriais e dos sentidos.
\end{abstract}

Palavras-chave: História da Geografia; Epistemologia; Cultura.

\begin{abstract}
:
The development of geography as science was consolidated in the 20th century to interpret society in various dimensions. The cultural dimension stands out among them, which gained importance and changed its conceptual and methodological bases. In this sense, the article's objective is to carry out a bibliographical review on cultural geography, bringing reflections on its role within geographic science, to show how its main ideas, characteristics, and transformations are. Furthermore, the concept of landscape, associated with cultural geography since its emergence, is also investigated.
\end{abstract}


Thus, traditional geography led to a material and descriptive perspective of culture in the landscape. From the second half of the 20th century onwards, new cultural geography will add symbolic, immaterial and sensing elements.

Keywords: History of Geography; Epistemology; Culture.

\section{INTRODUÇÃO}

A geografia, sendo uma ciência que dialoga com diferentes campos do conhecimento, traz às pessoas uma variedade de opções. No âmbito acadêmico, as linhas de pesquisa estão relacionadas com as respectivas vertentes do pensamento geográfico. De forma geral, são elas: a clássica, focada na descrição e empirismo; a teorética, alinhada ao quantitativo; a crítica, que carrega uma visão materialista histórica de mundo e, por fim, a humanista, voltada ao entendimento dos aspectos subjetivos e qualitativos. Neste artigo, investiga-se a história da geografia cultural e as transformações do conceito de paisagem.

Os estudos culturais surgem na Geografia por volta dos anos 1890, no contexto de estruturação desta ciência (CLAVAL, 2002). Paul Claval (2007), realiza um percurso por estes estudos, evidenciando fases pelas quais está vertente do pensamento geográfico caminha. $\mathrm{O}$ autor nos mostra que no mundo ocidental, países como Alemanha, Estados Unidos e França foram os precursores da geografia cultural. Na Alemanha, surgem os trabalhos de Ratzel, influenciados pelo pensamento de Darwin, sendo que este autor cunhou o termo antropogeografia. Nos Estados Unidos, os trabalhos de Carl Sauer, geógrafo fundador da escola de Berkeley, ganham destaque diante de uma geografia preocupada com o rigor metodológico e com as representações cartográficas. Por último, na França, evidenciam-se os trabalhos de Paul Vidal de La Blache, inspirados pelas ideias de Lamarck, tratando a antropogeografia como geografia humana.

Com o início da década de 1940, os estudos da geografia cultural clássica passam a perder campo diante das pesquisas voltadas para a geografia teorética ou quantitativa. Contudo, a partir da década de 1970, com as mudanças históricas, sociais, culturais e políticas provenientes da década anterior, a Geografia também se move para uma reformulação de seus ideais. Conforme apresenta Krüger (2010, p. 139), os acontecimentos da década de 1960, marcados por "revoluções comportamentais, surgimento da contracultura, revoluções nas artes, expansão da indústria cultural, eclosão dos movimentos sociais: estudantis, feministas, ambientais”, implicaram alterações no mundo todo e em diversas esferas das estruturas sociais. Além disso, a partir deste período acontece também um avanço de ditaduras militares na América Latina, como evidencia o trabalho de Fernandes e Moretti (2018).

Diante as transformações e novas necessidades deste período histórico, geógrafos e geógrafas passam a entender que para realizar análises sobre o espaço é necessário ir além das 
descrições e quantificações que marcaram a geografia tradicional e teorética. Nesse sentido, métodos como a fenomenologia, a hermenêutica e o materialismo histórico e dialético passam a ser introduzidos nos estudos geográficos, ocorrendo, deste modo, uma aproximação com outros campos do conhecimento. Como características destes novos trabalhos, tem-se a necessidade de superação do positivismo, bem como o distanciamento de ideais deterministas. Deste modo, começam as investigações sobre a dimensão histórica e cultural-simbólica dos sujeitos inseridos no espaço, envolvendo tanto a materialidade quanto a imaterialidade, criando-se uma geografia cultural radical e uma geografia cultural humanista.

A fim de propiciar elucidações sobre esta trajetória dos estudos culturais na Geografia, o presente artigo tem como objetivo realizar uma revisão bibliográfica sobre a geografia cultural, trazendo reflexões sobre seu papel dentro da ciência geográfica, com o intuito de mostrar as principais ideias, características e transformações. Para isso, investiga-se também o conceito de paisagem, que está associado à geografia cultural desde seu surgimento.

Considerando as mudanças que acontecem na ciência no decorrer do tempo, entende-se que as pesquisas que envolvem a história do pensamento são importantes para a continuidade da ciência geográfica. Ao esclarecer as origens de determinado pensamento ou vertente de estudo, facilita-se sua utilização, assim como a formulação de novas proposições para o fazer científico. Deste modo, entende-se que este trabalho não encerra o assunto, porém, pode auxiliar futuras investigações.

Nesse sentido, a discussão caminha, primeiramente, pelo entendimento de como surgiu o termo cultura nos estudos geográficos e de como este foi utilizado pelos geógrafos dentro da geografia cultural tradicional. Em um segundo momento, realiza-se uma exposição sobre como se deu a reformulação dos estudos culturais a partir da segunda metade do século XX. Por fim, discute-se o conceito de paisagem associado à história da geografia cultural.

\section{O INÍCIO DA GEOGRAFIA CULTURAL NO OCIDENTE: ALEMANHA, ESTADOS UNIDOS E FRANÇA}

Diante das reflexões epistemológicas trabalhadas por autores que estudam a geografia cultural e outros campos das ciências humanas, torna-se visível que o termo cultura é dotado de diversos sentidos e faz parte de um amplo debate (CLAVAL, 2002; CORRÊA, 2009 e LÉVY, 2015). A cultura associa-se a junção de comportamentos, conhecimentos, valores e técnicas acumuladas no percurso da vida dos indivíduos e grupos sociais dos quais estes indivíduos fazem parte. Relacionase com a transmissão de saberes e crenças de uma geração a outra e, por percorrer o espaço-tempo, essa transmissão não é estática, transformando-se através do contato com aquilo que é diferente (CLAVAL, 2007). 
De acordo com Claval (2007), o termo "geografia cultural” é introduzido pela primeira vez em uma obra que discorre sobre a geografia dos Estados Unidos. Esta obra foi publicada pelo geógrafo alemão Friedrich Ratzel (1844-1904) e o termo encontra-se presente no título do tomo II, denominado "A geografia cultural dos Estados Unidos da América do Norte com ênfase voltada para suas condições econômicas". Através de sua formação naturalista e dos aprendizados com Humboldt e Ritter, mestres da disciplina, Ratzel constrói uma divisão para os estudos dos homens e das civilizações, propondo para essa finalidade a antropogeografia. Deste modo, a antropogeografia seria guiada por três fundamentos: o mapeamento e a descrição das áreas onde os seres humanos residem, o entendimento de como a humanidade divide-se na superfície terrestre e a compreensão de como ocorre a influência da natureza em relação aos corpos e espíritos (BÜTTMAN, 1977, apud CLAVAL 2007). Conforme Ratzel (1990 [1914], p.102) afirma acerca das leis antropogeográficas “[...] cada povo carrega em si as características do seu território. Hoje a geografia do homem deve estudar os povos em relação às condições naturais às quais eles estão sujeitos, isto é, considera-los sempre unicamente sobre seu território." (grifos nossos).

Além disso, Ratzel também se dedicou à geografia política, para ele a existência e continuidade dos indivíduos e grupos estavam condicionadas à capacidade de mobilidade, aos elementos existentes no espaço e ao domínio de técnicas. "A seleção dos seres vivos pelo meio que Darwin postulava é substituída por Ratzel pela seleção das sociedades pelo espaço: a política impõese, assim, ao cultural" (CLAVAL, 2007, p. 23). As indagações inicialmente feitas por Ratzel fazem com que a cultura ganhe destaque perante a geografia humana, porém, ao comparar os Estados a organismos que estão constantemente comprometidos pela falta de espaço, seu interesse pela cultura torna-se fundamentalmente político (CLAVAL, 2007).

Claval (2002, p. 19), ressalta que do final do século XIX até o início dos anos cinquenta do século XX “os geógrafos adotavam uma perspectiva positivista ou naturalista, não estudando a dimensão psicológica ou mental da cultura". Segundo Claval (2007), é nesse cenário que os trabalhos de Ratzel recebem críticas por não apresentar um objeto que pudesse provar a existência de uma disciplina. Diante disso, o geógrafo alemão Otto Schlüter (1872-1959) traz contribuições importantes em uma tentativa de enunciar um objeto de estudo para a geografia humana: a paisagem, formada pela ação da natureza e dos homens. Schlüter considera a geografia humana como sendo o reflexo das transformações do espaço pelos grupos humanos, sua geografia é marcada por aquilo que autores alemães denominaram de Kulturlandschaft, termo que se refere à paisagem cultural ou humanizada.

Para Ratzel, o estudo geográfico da cultura confundia-se com o dos artefatos utilizados pelos homens para dominar o espaço. Para Schlüter e para a maioria dos geógrafos alemães das primeiras décadas do século, é a marca que os homens impõem à paisagem que constitui o objeto fundamental de todas as pesquisas. Esta marca é estruturada: o objeto da geografia é 
de apreender esta organização, de descrever aquilo que se qualifica desde então de morfologia da paisagem cultural e de compreender sua gênese. (CLAVAL, 2007, p. 24).

Claval (2007), analisa a produção geográfica cultural da Alemanha na primeira metade do século XX. Para o autor a influência advinda dos estudos de Darwin fez com que estes trabalhos iniciais dedicassem atenção aos utensílios, técnicas e ao consequente domínio do espaço pelos grupos sociais. Isso fez com que o entendimento sobre a construção destas práticas, seus conhecimentos e valores, não fossem investigados. Por outro lado, é também neste período que a dimensão cultural da paisagem fica marcada por conta de seus traços vigorosamente estruturados e estáveis.

Nesse sentido, a partir dos estudos de Carl Ortwin Sauer (1889-1975) e da escola de Berkeley, a discussão sobre cultura e sua dimensão no espaço geográfico entra em destaque nos Estados Unidos. Corrêa (2003) defende que a geografia cultural ganha identidade a partir da realização dos trabalhos de Sauer e seus adeptos. Por conta da preocupação com o rigor metodológico, com as coletas de dados e representações cartográficas, a geografia cultural dos Estados Unidos teria sido esquecida sem as pesquisas de Sauer. O geógrafo começou a abordar a questão trinta anos após os primeiros trabalhos dos alemães nessa área (CLAVAL, 2007).

Sauer, antes de realizar seus estudos e acabar ministrando aulas na Universidade de Berkeley, passou parte de sua vida na Alemanha, possuindo, deste modo, afinidade com a língua e pensamento alemães. Essa ligação se torna nítida a partir da publicação de "A morfologia da paisagem", onde o autor retoma a expressão de mesmo nome inicialmente proposta e popularizada pelo geógrafo alemão Otto Karl Siegfried Passarge (1866-1958) (CLAVAL, 2007).

Para Sauer (2003, p. 22), “a geografia cultural se interessa, portanto, pelas obras humanas que se inscrevem na superfície terrestre e imprimem uma expressão característica”. O autor fundamentava-se no historicismo, iniciando na geografia americana uma abordagem onde o homem e as transformações na paisagem mostram-se no sentido temporal, relacionando as mudanças ao conceito de cultura (Figura 1).

Deste modo, Sauer se mostrava contrário ao determinismo ambiental, afirmando a condição do homem de sobressair perante a natureza (SPETH, 2011; MATHEWSON e SEEMANN, 2008):

Nossa seção da realidade, ingenuamente selecionada, a paisagem, está sofrendo uma mudança múltipla. Esse contato do homem com seu lar mutável, como é expresso por meio da paisagem cultural, é nosso campo de trabalho. Preocupamo-nos com a importância do sítio em relação ao homem e com a transformação desse sítio. Ao mesmo tempo, lidamos com a inter-relação do grupo, ou culturas, e sítio, como expressos nas várias paisagens do mundo. (SAUER, 1998 [1925], p. 68). 


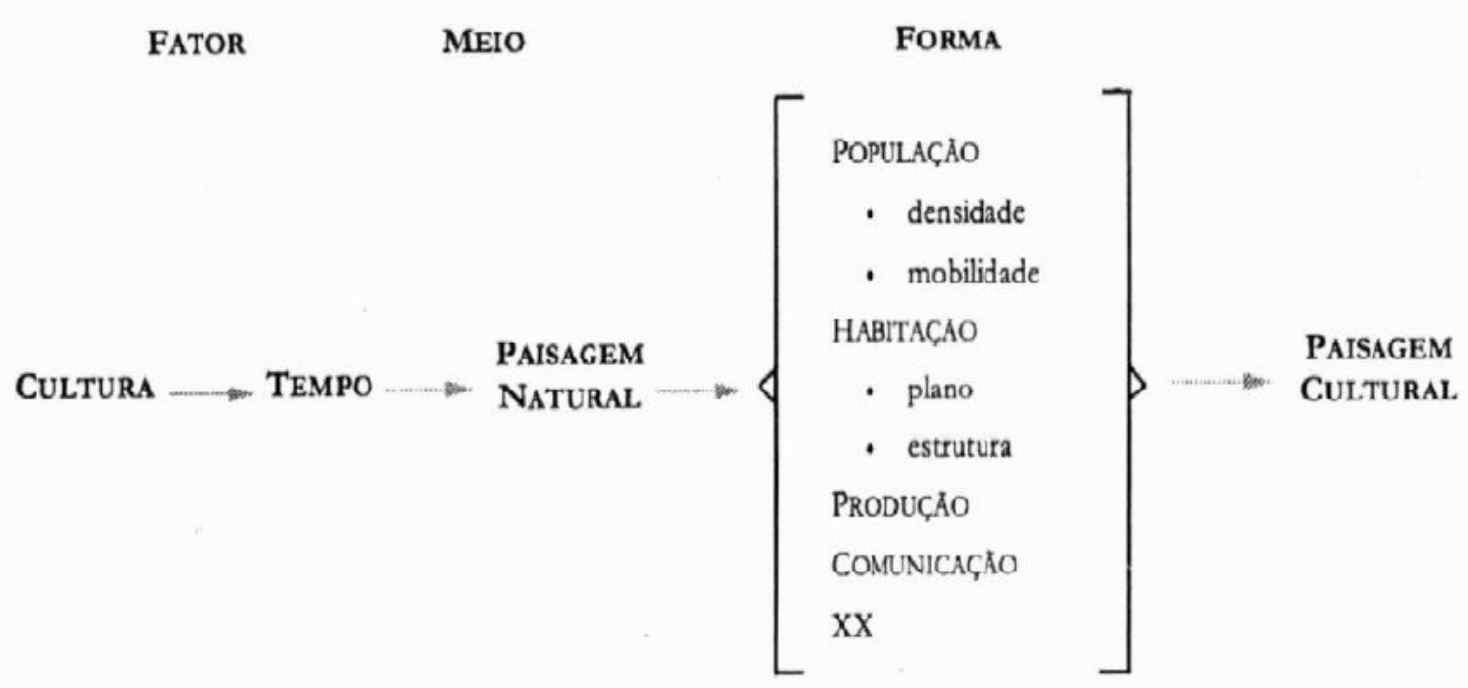

Figura 1 - Estrutura da paisagem segundo Carl Sauer.

Fonte: (SAUER, 1998 [1925], p. 58).

O interesse pelo historicismo por parte de Sauer surge a partir de sua proximidade com a antropologia americana. O autor critica as civilizações modernas, considerando-as indiferentes a condição humana e à natureza. Para ele, a geografia limita-se ao que é identificável na superfície da terra, ressaltando, assim como os geógrafos alemães, o caráter material da cultura, não abordando as dimensões sociais e subjetivas da mesma. Ao mesmo tempo, Sauer possui um interesse ecológico, destacando que a cultura é constituída por fatores biológicos (fauna e flora) que as sociedades, com o passar do tempo, conheceram e começaram a utilizar visando um ambiente mais produtivo. As transformações do espaço causadas pela interferência humana não são inocentes, podendo causar graves desastres. É nesse sentido que as preocupações de Sauer e da escola de Berkeley encontramse atuais (CLAVAL, 2007).

Mesmo com o avanço em alguns pensamentos, como a necessária superação do determinismo ambiental e a preocupação ecológica, Sauer e seus discípulos receberam críticas. Duncan (2003), ressalta que os geógrafos culturais americanos aceitaram a cultura como uma entidade supra-orgânica. De acordo com Corrêa (2001, p. 25), “a cultura constitui-se, assim, um nível independente da realidade, externa ao indivíduo, explicável por si própria, dentro de uma visão holística". Deste modo, as críticas caminhavam no sentido de não concordar com o fato de que a cultura era, sobretudo, controladora das ações humanas. "Em realidade, ao abandonar o determinismo ambiental, Sauer e seus discípulos acabaram engajados no determinismo cultural, outra versão do darwinismo social contra o qual Sauer tanto lutara" (CORRÊA, 2001, p. 27). Ainda assim, os trabalhos de Sauer e da escola de Berkeley são importantes para a continuidade da geografia cultural. 
Além de Alemanha e Estados Unidos, os estudos culturais iniciais da geografia ocidental ganham destaque também na França, introduzidos pelo pensamento de Paul Vidal de La Blache (1845-1918) (ZANATA, 2008). Claval (2007), afirma que este geógrafo parte da ideia de geografia humana proposta por Ratzel, estudando as relações do meio e das sociedades humanas. Assim como os geógrafos alemães e americanos, ele também se interessa pelo conjunto de técnicas e utensílios que o ser humano detém para a transformação de determinado contexto onde reside. Todavia, La Blache (2012 [1911], p. 132) defende que a análise destes fatores não faz sentido quando não enquadrada dentro daquilo que denomina de gêneros de vida.

\footnotetext{
Um gênero de vida constituído implica uma ação metódica e contínua, que age fortemente sobre a natureza ou, para falar como geógrafo, sobre a fisionomia das áreas. Sem dúvida, a ação do homem se faz sentir sobre seu meio desde o dia em que sua mão se armou de um instrumento [...] o efeito de hábitos organizados e sistemáticos que esculpem cada vez mais profundamente seus sulcos, impondo-se pela força adquirida por gerações sucessivas, imprimindo suas marcas nos espíritos, direcionando em um sentido determinado todas as forças do progresso.
}

Assim como Ratzel, La Blache destaca o papel das técnicas no processo de dominação do espaço pelo homem. Contudo, a noção de gênero propõe que a ação humana seja delineada pelo que se encontra disponível ou não na natureza, assim como pelo desenvolvimento das técnicas, da cultura e da civilização dos grupos sociais, distanciando-se do determinismo geográfico e aproximando-se do possibilismo. "O estudo da difusão das técnicas permite compreender o arsenal à disposição de cada grupo. Mas o gênero de vida tem dimensões sociais e ideológicas que estão indissociavelmente ligadas a seu aspecto ecológico" (CLAVAL, 2007, p. 35).

De acordo com Claval (2007), a visão de La Blache é inspirada pela tônica naturalista que rondava o mundo intelectual nos primeiros anos do século XX. Devido à influência do pensamento de Lamarck e por ser uma característica da geografia da época, seus trabalhos tinham como marca a descrição e explicação dos hábitos humanos no espaço, formando, portanto, a paisagem humanizada. Além disso, o autor se dedicava a explicar a formação dos lugares, afirmando que a ciência geográfica é a ciência dos lugares, não dos homens. A noção de gênero de vida inicia na geografia francesa um campo que progressivamente se dedica aos comportamentos humanos, cada vez mais complexos e heterogêneos.

Ainda na geografia francesa deste período, destacam-se também autores como Jean Brunhes (1869-1930) e Pierre Deffontaines (1894-1978). O primeiro, apesar de ter sido um dos primeiros alunos de Vidal de La Blache, praticava uma geografia diferente da de outros vidalianos, procurando ressaltar tanto os elementos funcionais do espaço como os de valores simbólicos. Já o segundo se aproxima de pesquisas feitas por etnógrafos e folcloristas. Estes autores seguiram o pensamento de La Blache principalmente no que se refere ao gênero de vida, sendo cruciais para direcionar os estudos culturais para o espaço agrário (CLAVAL, 2007). Nesse sentido, ocorrem certas mudanças dentro da 
geografia humana francesa, nas palavras de Claval (2007, p. 35) "naturalista pela sua origem e suas justificações, ela deriva rapidamente para posições mais humanistas". O período entre final do século XIX e primeira metade do século XX viu surgir uma geografia cultural preocupada com as técnicas, com a organização dos elementos humanos no espaço e suas marcas na paisagem (Figura 2).

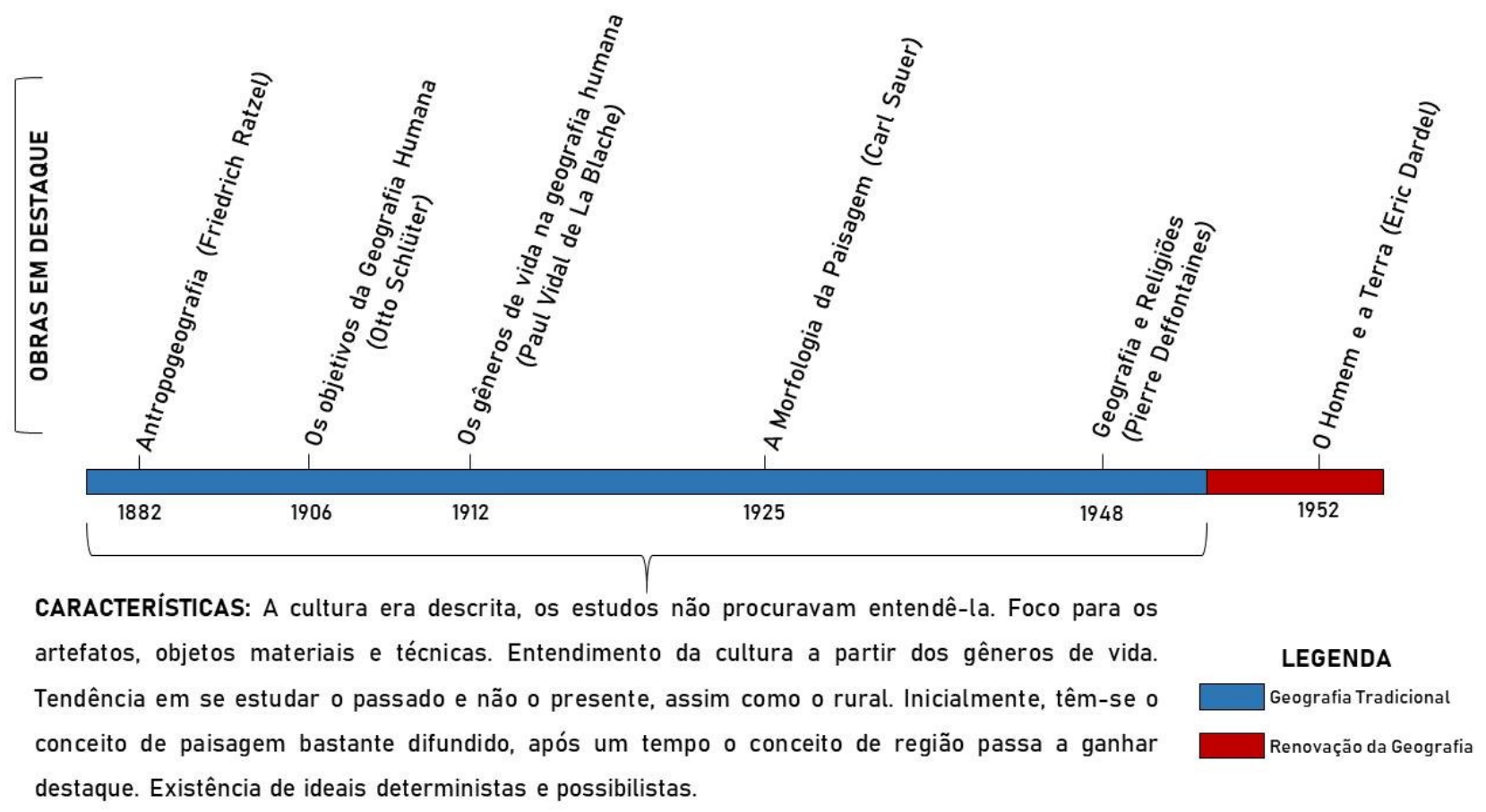

Figura 2 - Linha do tempo da geografia cultural tradicional.

Fonte: Elaborado pelos autores.

Claval (2007), diz que a preocupação dos geógrafos que se interessavam pela cultura neste período voltava-se muito mais à descrição do mundo do que sua compreensão propriamente dita, além disso, não concediam importância aos problemas dos grupos sociais, deixando de lado suas manifestações políticas ou simbólicas. O passado era mais investigado do que o presente, devido ao distanciamento do mundo moderno, complexo e industrial. O subjetivo era praticamente irrelevante frente aos aspectos materiais.

Segundo Claval (2007), os trabalhos da geografia cultural tenderam a seguir a ideia de gêneros de vida e descrição até os anos 1970, mesmo com a publicação de Eric Dardel ${ }^{1}$. Todavia, devido ao desenvolvimento da sociedade - levando em consideração a padronização das técnicas e o aumento da industrialização nos países -, este modo de pensar entra em desuso por não responder questões importantes do mundo moderno, relacionadas à crescente heterogeneidade do espaço. É nesse sentido que o campo da geografia cultural se estrutura para novas formas de análises.

\footnotetext{
${ }^{1}$ O homem e a terra: a natureza da realidade geográfica. Obra publicada em 1952, que viria influenciar a reformulação da geografia cultural.
} 


\section{A REFORMULAÇÃO DA GEOGRAFIA CULTURAL A PARTIR DA INTRODUÇÃO DE NOVOS CAMINHOS}

Claval (2011), afirma que a concepção positivista que marcou a geografia cultural a partir de estudos feitos na primeira metade do século XX, entra em declínio no final da década de 1960. Os contrários eram geógrafos e geógrafas que procuravam novos caminhos para as análises, como a fenomenologia, o materialismo histórico-dialético e a hermenêutica. Como aponta Holzer (2013), é importante destacar o ambiente intelectual da época: movimento hippie, revoltas estudantis e questionamentos sobre os padrões culturais e políticos impostos. Deste modo, estas filosofias críticas ao positivismo e à quantificação começaram a guiar os novos estudos culturais na geografia.

Em seu trabalho onde faz uma revisão sobre a geografia humanista ${ }^{2}$, Holzer (2013) nos mostra que os estudos de caráter fenomenológico já eram gestados na geografia cultural antes mesmo da reformulação que ocorreu na segunda metade do século XX. A ideia de estudar geograficamente a imaginação humana, superando a visão cartesiana e positivista, remete aos anos 1920. Segundo Amorim (2014), a fenomenologia está presente na geografia desde a geografia tradicional. O referido autor destaca que os trabalhos de Carl Sauer, J.K. Wright, W. Kirk, Eric Dardel, E. G. Hoskins e D. Lowenthal foram precursores da geografia humanista. Holzer (2013), reforça dizendo que a obra de Eric Dardel influenciou autores como Edward Relph e Yi-Fu Tuan, possuindo papel fundamental na concepção do conceito de lugar, um importante conceito para a geografia humanista.

Holzer (2013) afirma que o artigo "Geografia Humanística”, publicado por Yi-Fu Tuan em julho de 1976, é considerado um marco para a independência desta vertente da geografia. Neste trabalho o autor traz algumas proposições sobre como deve ser as atitudes de um geógrafo voltado às preocupações humanistas, "a geografia humanística procura um entendimento do mundo humano através do estudo das relações das pessoas com a natureza, do seu comportamento geográfico bem como dos seus sentimentos e ideias a respeito do espaço e do lugar” (TUAN, 1985, p. 143). Tuan (1985), diz que o entendimento de como o espaço se transforma em um lugar especificamente humano é dever do geógrafo humanista, fazendo-se necessário aderir a interesses humanísticos, como: a experiência, a qualidade da ligação emocional com os objetos materiais, a característica e função dos símbolos na construção de um lugar. A ligação sentimental e perceptiva do ser humano com o meio físico é fator importante no desenvolvimento da pesquisa humanística e qualitativa. Através do entendimento da percepção e do sentimento, podemos observar as diferentes experiências que irão refletir as formas de adaptação, identidade e as atividades de indivíduos e grupos sociais em determinados espaços.

\footnotetext{
${ }^{2}$ Para mais estudos, autores e autoras desta nova fase da ciência geográfica, consultar Valcárcel (2000) e Claval (2001). 
Além deste trabalho de Tuan, Holzer (2013) destaca dois eventos que aconteceram em 1961 e que também possuem importância para a criação da identidade da geografia humanista. O primeiro se refere à revisão realizada por David Lowenthal, um ex-aluno de Sauer, sobre a obra de John Kirtland Wright. Esta revisão buscou uma renovação da geografia cultural que, frente ao domínio da geografia quantitativa e comportamental, perdia espaço na América do Norte. Segundo Lowenthal (1985, p. 112) "a visão do mundo que os geógrafos constroem deve ser criada a cada nova geração, não somente porque a realidade muda, mas também porque as preocupações humanas variam”. Por sua vez, o segundo evento se relaciona à proposição de outro trabalho de Yi-Fu Tuan que, inspirado em Bachelard, realiza uma geografia aplicada ao entendimento da relação de afetividade entre o homem e o meio natural, ou seja, trata-se do conceito denominado por Tuan como topofilia. "A geografia se dedicaria ao estudo das vivências, que se expandem do lar para paisagens mais amplas, da paisagem humanizada para os cenários mais selvagens" (HOLZER, 2013, p. 138).

Outros também foram importantes neste período de reformulações. Conforme aponta Holzer (2013), foi Edward Relph quem primeiro colocou em um artigo as possíveis contribuições da fenomenologia como suporte para a união dos geógrafos preocupados com os aspectos subjetivos da espacialidade. Holzer (2013, p. 140), diz que "Relph previa pelo menos duas consequências imediatas do uso da fenomenologia na geografia: uma visão holística e unificadora da relação homem-natureza e uma crítica ao cientificismo e ao positivismo". Ainda segundo Holzer (2013), os autores Mercer e Powell (1972) e a autora Anne Buttimer (1974) foram de igual importância para este momento. Os primeiros realizaram uma sistematização sobre métodos até então não convencionais para a subjetividade na geografia, como a fenomenologia. Buttimer (1985), por sua vez, realizou um trabalho que relaciona a fenomenologia e o existencialismo à ciência geográfica. Deste modo, o último passo para a renovação epistemológica estava dado.

A geografia cultural voltada para a fenomenologia continua a partir da década de 1980 , preocupada com valores humanistas e sendo contrária ao positivismo. Como aponta Holzer (2013, p. 146) "nunca houve um afastamento efetivo da geografia cultural, mas uma procura em se distinguir dos que se utilizavam do positivismo como método". Holzer (2013), ainda reforça que sempre houve a sintonia com a questão ambiental, dizendo que foi dentro do humanismo que os problemas ambientais ganharam notoriedade e avançaram de forma conceitual na geografia.

Além do aporte humanístico, destaca-se também a contribuição da geografia cultural relacionada ao materialismo histórico e dialético, como é possível ver em Zanata (2008) e Cosgrove (2013). Em 1983, Denis Cosgrove publica “Em direção a uma geografia cultural radical: problemas na teoria", artigo publicado no Brasil em junho de 2013, no periódico Espaço e Cultura. Neste trabalho onde faz uma revisão sobre a geografia cultura e o marxismo, o geógrafo cultural britânico indica suas ligações e também seus problemas. 
O marxismo e a geografia cultural partem deste mesmo ponto ontológico, indo contra qualquer forma de determinismo, seja cultural ou natural, e buscam um entendimento da relação entre seres humanos e natureza a partir do ponto de vista histórico (COSGROVE, 2013). De acordo com Cosgrove (2013), os conceitos desenvolvidos pelos geógrafos Carl Sauer e La Blache dependem da compreensão da natureza e cultura, em sua relação dialética. Estes autores tradicionais da geografia cultural, mesmo compartilhando de algumas premissas do materialismo histórico, não incorporaram de forma eficaz esta temática dentro do pensamento geográfico e tenderam a tratar a cultura como fato puramente inventivo do ser humano. A abordagem dialética entre natureza e cultura foi, portanto, logo de início isolada. Ao mesmo tempo, Cosgrove também destaca alguns problemas quanto a este caminho. "Manter a dialética da cultura e natureza sem cair no idealismo ou no materialismo reducionista é o principal problema teórico para o materialismo histórico" (THOMPSON, 1978, apud COSGROVE, 2013, p. 6).

Nesse sentido, Cosgrove (2013) destaca a centralidade de Antonio Gramsci e György Lukács nos estudos sobre a cultura, pois ambos reconheceram que esta tem papel fundamental na construção da consciência de classes. Lukács tratou a cultura literária e artística, enquanto Gramsci envolveu-se com a questão do entendimento da consciência de classes dentro de determinada particularidade geográfica. De acordo com Cosgrove (2013, p. 18), "na sociedade de classes, a cultura é o produto da experiência de classes. Os reflexos do senso comum de cada classe sobre sua própria experiência material é parte de sua luta com outras classes".

A influência do materialismo histórico e dialético se manifesta, principalmente, por meio da compreensão da cultura, simultaneamente, como um reflexo e condição social; da oposição a qualquer forma de determinismo ou explicação linear causal e do reconhecimento da dimensão histórica na relação entre os seres humanos e a natureza (ZANATA, 2008, p. 231).

As visões destes dois autores que Cosgrove resgata constituem maneiras de se pensar a cultura por meio do materialismo histórico e dialético. Contudo, existem também outros trabalhos de igual importância. De modo geral, Cosgrove e Jackson (2003) indicam os trabalhos advindos de Stuart Hall e do Centro de Estudos Culturais contemporâneos da Universidade de Birmingham, como necessários para a compreensão e investigação de diversos temas. Entre estes temas, destacam-se aqueles voltados para o entendimento das minorias, que tratam sobre assuntos emergentes e urgentes, como a desigualdade de gênero, o racismo e a homofobia.

Outro sociólogo que também trabalhou a cultura a partir da utilização do materialismo histórico e dialético foi Raymond Williams. Para Williams (2002), a hegemonia existente no mundo, bem como o sistema hierárquico não deve ser trabalhada através de uma simples opinião ou manipulação. $\mathrm{O}$ autor defende que se trata de um conjunto de significados e valores que a partir do momento em que são utilizados, através da ação humana, confirmam-se uns aos outros. Este modelo 
acaba provocando certa imobilidade dentro das próprias vidas dos sujeitos que constituem a sociedade, uma vez que este sistema de significados delimita ações que são reproduzidas cotidianamente e necessárias para a subsistência. Em todo caso, o autor não considera este um sistema estático. "Pelo contrário, só podemos entender uma cultura dominante e eficaz se compreendermos o verdadeiro processo social da qual ela depende, isto é, o processo de incorporação" (WILLIAMS, 2002, p. 13).

Claval (2001), afirma que para os geógrafos críticos a sociedade não é uma organização que existe desde sempre, suas regras advêm de iniciativas humanas. Quando estas relações humanas geram desigualdades sociais, existe o descontentamento com a imposição e a luta por justiça social. Portanto, “os geógrafos não devem desviar-se da análise da contestação social, do desenvolvimento de movimentos de oposição e do surgimento de culturas críticas e de contraculturas" (CLAVAL, 2001, p. 45-46). Com a renovação da geografia cultural a partir da segunda metade do século XX, percebe-se um largo campo de estudos se criando para a geografia (Figura 3).

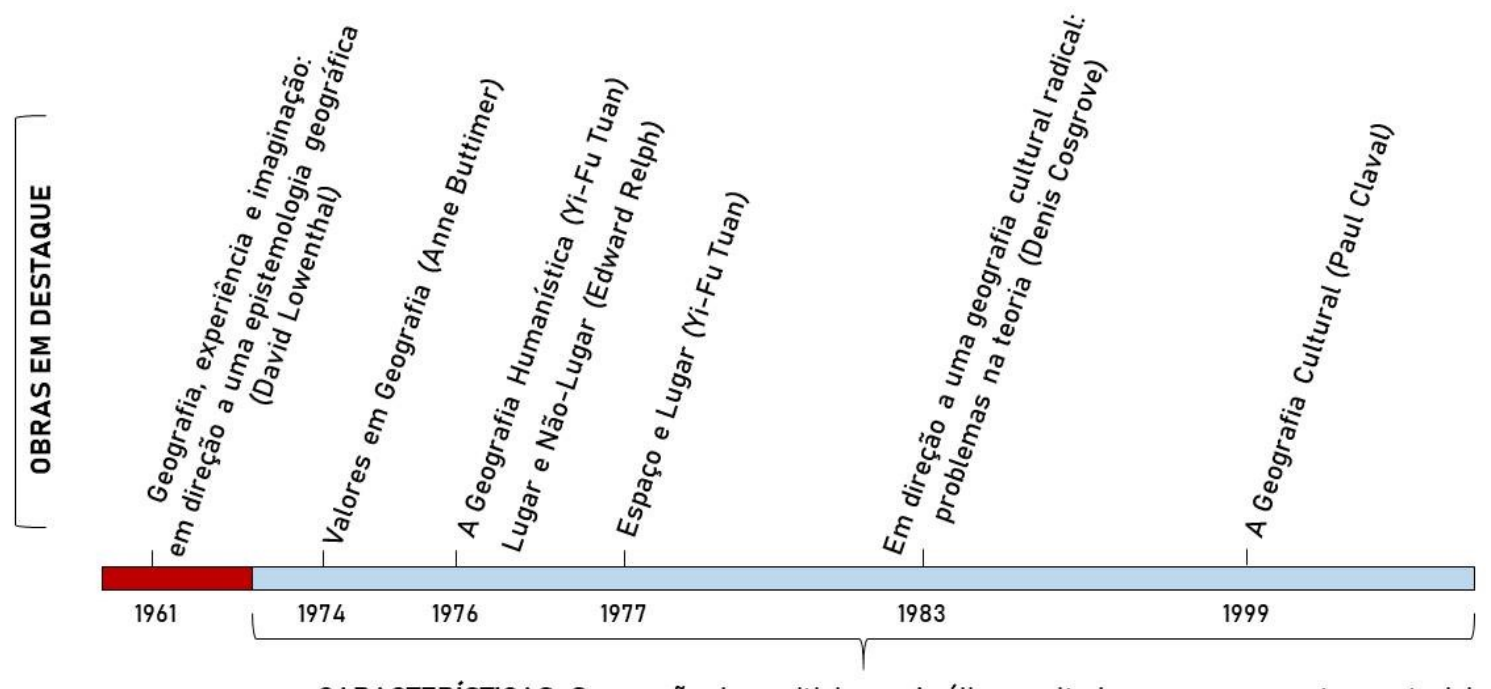

LEGENDA

CARACTERISTICAS: Superação do positivismo. Análises voltadas para os aspectos materiais e imateriais da cultura. Ênfase nas experiências e vivências dos indivíduos e entendimento a

Renovação da Geografia partir do subjetivo. Retomada da utilização da paisagem e conceito de lugar bastante difundido. Aproximação com outras filosofias, como a fenomenologia, a hermenêutica e o materialismo histórico e dialético. Abertura a novas técnicas, objetivos e temas de pesquisas.

Figura 3 - Linha do tempo da nova geografia cultural.

Fonte: Elaborado pelos autores.

Lévy (2015) diz que essa "virada" da geografia cultural está entrelaçada a outros movimentos, como a virada linguística e o pós-modernismo. Em seu artigo, intitulado "Qual o sentido da geografia cultural?", este autor aponta alguns problemas que precisam ser trabalhados no desenvolvimento epistemológico sobre estes estudos na geografia. Todavia, acredita-se que estas 
novas perspectivas de análises têm sido relevantes para a compreensão das transformações espaciais das últimas décadas ${ }^{3}$.

Essa mudança é fundamental. Por significar que a abordagem cultural não é um aspecto limitado, um capítulo especial da geografia humana, ela constitui a única perspectiva que permite reconstruir nossa disciplina de acordo com as orientações fenomenológicas e críticas das ciências humanas contemporâneas e das humanidades - o limite entre esses dois domínios deixa de ser tão evidente quanto no passado (CLAVAL, 2001, p. 47).

Tanto o materialismo histórico e dialético quanto a fenomenologia podem ser utilizados como suporte para o entendimento das experiências dos sujeitos no espaço, assim como das relações sociais, dos simbolismos e manifestações que existem entre as diversas representações culturais. Uma cooperação entre estas diferentes formas de análise podem ser benéficas para o desenvolvimento da geografia cultural e da ciência geográfica, uma vez que a geografia se mostra como campo de estudo para diferentes temas e propostas.

\section{O CONCEITO DE PAISAGEM E SUA RELAÇÃO COM A GEOGRAFIA CULTURAL}

Como visto no começo deste texto, o conceito de paisagem está presente desde o início dos estudos voltados para a geografia cultural. Inicialmente entendida a partir do objetivo e material, ela se transforma, sendo reinterpretada através dos diferentes sentidos, subjetividades e dimensões simbólicas do espaço. Considerando que o saber científico está atrelado aos momentos históricos, aos aspectos políticos, econômicos, culturais e sociais de determinado período, a compreensão sobre paisagem passa por mudanças em consonância com as fases do pensamento geográfico. Sabendo disso, a intenção desta seção não consiste em encerrar estes caminhos, mas sim em trazer, de forma geral, alguns aspectos e momentos da relação da paisagem com os estudos da geografia cultural.

De acordo com Luchiari (2001), a ideia de paisagem começou a emergir no ocidente a partir do século XVI. Isso aconteceu por intermédio de novas técnicas associadas à pintura, chegando também até a literatura. Esse movimento de descoberta da paisagem moldou uma diferente ligação das pessoas com a natureza e rompeu com a visão dominante voltada para explicações teológicas. Uma vez que a paisagem relaciona-se também com aquilo que existe em nossas mentes (MEINIG, 2002), podemos entender o importante papel que a pintura teve para o desenvolvimento deste conceito. Nesse período, as pinturas representavam a beleza da natureza, traziam o ar bucólico das paisagens intocadas. Logo, as pessoas que tinham a posição social e conseguiam acesso a esse movimento artístico, passavam a observar a própria natureza a partir dos códigos instituídos pelas telas. Essa relação da sociedade com o espaço se transformou a partir de uma construção cultural e

\footnotetext{
${ }^{3}$ Para mais discussões sobre esse e outros caminhos da ciência geográfica, consultar a obra Geografia e Modernidade, publicada em 1996 pelo geógrafo brasileiro Paulo César da Costa Gomes.
} 
social, fez com que a observação, a contemplação, a valorização estética das paisagens naturais fossem influenciada pelo ato de pintar (SALGUEIRO, 2001).

Luchiari (2001), continua nos dizendo que até o século XVIII a paisagem foi tratada relacionada à pintura. Este fato condicionou significativamente a construção do conceito pelas ciências da época, assim como aconteceu com a geografia. Além da relação com a representação das pinturas, é possível ver em Salgueiro (2001) e em Besse (2014) que a paisagem da geografia tradicional aparece relacionada à fisionomia de certa área, sendo constituída e interpretada através da forma visível. Besse (2014), delimita dois polos extremos para o entendimento da formulação do conceito, os quais ele denomina de subjetivistas e realistas.

Tanto um subjetivista quanto um realista reconhecem que a paisagem é da ordem do visível.
A verdadeira questão é a do estatuto atribuído ao visível, da sua função, e mesmo da sua
significação. Grosso modo: é o espectador que define a paisagem? Neste caso, o visível é
relativo a um ponto de vista, a um enquadramento, é uma imagem. Ou há o visível, a
paisagem, havendo ou não um olhar? Neste caso, o visível e a paisagem são pensados como
objetivos, como uma face exterior, um rosto, uma fisionomia, e então o problema do
espectador eventual consiste em se ajustar perceptivamente e intelectualmente a esta
fisionomia: a paisagem não é uma imagem, é uma forma. (BESSE, 2014, p. 64-65).

Nesse sentido, a paisagem começa a contar com uma concepção polissêmica, ganhando destaque na Alemanha do século XIX no momento de constituição da geografia como disciplina científica (LUCHIARI, 2001). Os geógrafos alemães Alexander von Humboldt e Carl Ritter buscavam a sistematização do conhecimento geográfico no século XIX. De modo geral, enquanto Humboldt utilizava a paisagem em sua totalidade, fazendo descrições e relacionando os elementos naturais e humanos, Carl Ritter dedicava-se às descrições regionais construindo a sua geografia comparada. A visão positivista é predominante neste período e a geografia alemã passa a adotar o conceito de paisagem como objeto de estudo (SCHIER, 2003).

Outros dois geógrafos alemães, já lembrados neste capítulo, também marcaram o estudo geográfico tradicional da paisagem, são eles: Friedrich Ratzel e Otto Schlüter. Ratzel tratou o conceito considerando os elementos fixos naturais, como os rios e montanhas, e os elementos móveis, em geral advindos da criação humana. De certa forma, o geógrafo distancia os processos naturais dos humanos e passa a compreender a paisagem de forma antropogênica, considerando a transmissão dos artefatos entre os grupos sociais. Por sua vez, Schlüter, especializou-se no estudo dos estabelecimentos humanos, dedicando parte de seu trabalho aos aspectos relacionados à paisagem cultural (SCHIER, 2003). Portanto, “os estudos de paisagem, inicialmente muito focados na descrição das formas físicas da superfície terrestre, foram progressivamente incorporando os dados da transformação humana do ambiente no tempo, com a individualização das paisagens culturais face às naturais" (SALGUEIRO, 2001, p. 41). 
Como visto anteriormente, a influência da geografia alemã chegou até Carl Sauer nos Estados Unidos, sendo importante para seus estudos relacionados à morfologia da paisagem. Schier (2003, p. 83) diz que para Sauer "a paisagem cultural representa, consequentemente, uma materialização de pensamentos e ações humanas, mas nunca sai do seu caráter físico-material, fato que aponta pela forte influência do positivismo descritivo da época". Sauer entendia a paisagem como central para os estudos da geografia, "a paisagem Saueriana, isto é, a paisagem cultural, era o resultado da ação da cultura, o agente modelador da paisagem natural” (CORRÊA, 2014, p. 41).

Quanto à geografia francesa, a noção de gênero de vida proposta por Paul Vidal de La Blache acaba se aproximando mais do conceito de região do que propriamente da paisagem. De acordo com Name (2010, p. 166), pode-se definir o conceito de gênero de vida como "dinâmico que resume um processo: é a forma específica de cada grupo, sua 'maneira de ser'; esses grupos realizam uma adaptação ao meio a partir de uma herança cultural e instrumental, transmitida pelo hábito”. Deste modo, a partir de seus estudos, entende-se que cada gênero de vida associa-se a uma paisagem-tipo. Todavia, a paisagem é citada eventualmente em sua obra, confundindo-se com seu conceito mais importante: a região (NAME, 2010). Destacam-se também nesses estudos Albert Demangeon, Jean Gottmann, Jean Brunhes e Pierre Deffontaines, como é possível ver em Furlanetto e Kozel (2014) e em Claval (2007).

Portanto, pode-se perceber um interesse marcante pelo estudo da paisagem na geografia cultural tradicional, pelo menos até meados do século XX. Todavia, como apontado por Claval (2007) e Corrêa (2012), o período situado aproximadamente entre 1940 e 1970, está marcado por uma diminuição do interesse pelos estudos culturais na geografia e pela paisagem como objeto de estudo. Os acontecimentos voltados para a Segunda Guerra Mundial, assim como a retomada do avanço capitalista nos anos 1950, provocaram mudanças significativas, como a transformação das paisagens rurais e urbanas. Diante destas mutações da paisagem, Corrêa (2012) distingue duas fases de estudos neste período. O autor diz que os geógrafos começam a se interessar pelas análises regionais (1940 e 1955) e pela "revolução teorética-quantitativa" (1955-1970), que utilizou modelos matemáticos para alimentar questões sobre o entendimento capitalista acerca do espaço. Este novo movimento fez com que a paisagem fosse esquecida, pois o conceito passou a ser visto como abordagem do passado.

Deste modo, a retomada da paisagem, que acontece a partir de 1970, é marcada pelo movimento de renovação da geografia. Como visto anteriormente, esses novos estudos se fazem com base em outras filosofias, como a fenomenologia, a hermenêutica e o materialismo histórico e dialético, e acontecem nas humanidades como um todo. O objetivo deste movimento é romper com a tradição positivista e neo-positivista então presentes nos estudos científicos. Diante disso, a concepção de paisagem da geografia cultural tradicional recebe diversas críticas, já não é suficiente o entendimento do conceito a partir da análise concordante entre a relação sociedade (passiva) e 
natureza (CORRÊA, 2012). As contribuições pós-1970, referentes aos estudos culturais da paisagem, são inúmeras, existindo grande referencial bibliográfico sobre estes novos caminhos ${ }^{4}$.

Apresentaremos agora algumas reflexões sobre os entendimentos da nova geografia cultural relacionados à paisagem, com a consciência que a discussão que se segue não esgota o assunto. Intencionando exemplificar um pouco a reformulação do pensamento e guiar o presente artigo, levaremos como base o trabalho de Corrêa (2012). Sobre estas reformulações, Corrêa (2012, p. 32) destaca cinco grupos temáticos: "paisagem, polivocalidade e iconografia; paisagem, diferenciação social e poder; paisagem: marca, matriz e mudanças; paisagem da simulação e, finalmente, paisagem e literatura". Seguiremos discutindo um pouco do que cada grupo interpreta e representa para os estudos pós-1970.

A respeito do primeiro grupo "paisagem, polivocalidade e iconografia", Corrêa (2012, p. 33) diz que "a polivocalidade constitui-se em antídoto contra a retórica da verdade daqueles que querem impor uma única interpretação a respeito de processos e formas, entre eles a paisagem". Diante disso, têm-se a criação de diferentes significados, cabendo aqui, mais uma vez, a reflexão de Meinig (2002, p. 35) "qualquer paisagem é composta não apenas por aquilo que está a frente de nossos olhos, mas também por aquilo que se esconde em nossas mentes". Sendo assim, uma mesma paisagem experienciada por diferentes pessoas pode produzir diferentes interpretações e iconografias.

Quanto ao grupo referente à "paisagem, diferenciação social e poder", Corrêa (2012) destaca o trabalho de Cosgrove (2012) que foi construído com base na sugestão de Raymond Williams. Cosgrove coloca a paisagem como sendo um conceito de grande importância para essa nova fase:

\begin{abstract}
Paisagem é um conceito unicamente valioso para uma geografia efetivamente humana. Ao contrário do conceito de lugar, lembra-nos sobre a nossa posição no esquema da natureza. Ao contrário de meio ambiente ou espaço, lembra-nos que apenas por meio da consciência e da razão humanas esse esquema é conhecido por nós, e somente através da técnica podemos participar dela como seres humanos. Ao mesmo tempo, paisagem lembra-nos que a geografia está em toda parte, que é uma fonte constante de beleza e feiura, de acertos e erros, de alegria e sofrimento, tanto quanto é de ganho e perda. (COSGROVE, 2012, p. 224).
\end{abstract}

Diante disso, o autor classifica a paisagem segundo alguns tipos. O primeiro tipo associa-se às paisagens da cultura dominante, estas paisagens são construídas por grupos hegemônicos, que detém o poder e realiza uma dominação "baseada objetivamente no controle dos meios de vida: terra, capital, matérias primas e força de trabalho" (COSGROVE, 2012, p. 230). Essas paisagens apresentam-se diante de grandiosas construções e domínios. Já o segundo tipo proposto pelo autor é o das paisagens alternativas, que abrange as residuais, emergentes e excluídas. Exemplificando estas classificações, Corrêa (2012) relaciona às paisagens residuais aos cortiços característicos de áreas

\footnotetext{
${ }^{4}$ Consultar Corrêa (1997) e Claval (2004) para maior compreensão das transformações das abordagens geográficas culturais sobre a paisagem.
} 
periféricas das grandes metrópoles, as emergentes como aquelas que demonstram possibilidades futuras e as excluídas, que podem ser encontradas nas favelas.

Mesmo que, em um movimento de mudança na escala de observação/análise, determinada paisagem alternativa local possa parecer dominante, vai continuar em domínio de outra. De acordo com Cosgrove (2012, p. 233) “o antigo depósito de bondes pode ser uma mesquita, pintura brilhante, ritmos reggae e pôsteres evangélicos podem estar presentes em uma rua de residências vitorianas. Porém, por mais dominante localmente que possa ser uma cultura alternativa, ela continua subdominante à cultura nacional oficial". Para Corrêa (2012), o debate proposto por Cosgrove enriquece a paisagem, a coloca no contexto social, investiga suas temporalidades e espacialidades, demonstrando seu movimento.

Já o terceiro grupo "paisagem marca, matriz e mudanças", abrange o pensamento de Augustin Berque. Em seu artigo “Augustin Berque: um trajeto pela paisagem”, Holzer (2004), faz uma revisão bibliográfica sobre o pensamento do geógrafo orientalista, que se autodenomina assim devido à sua intensa relação com o Japão e com a cultura oriental, influência que acaba refletindo em suas obras.

A paisagem é uma marca, porque exprime uma civilização, mas é também uma matriz,
porque participa de esquemas de percepção, de concepção e de ação - isto é, da cultura - que
canalizam, e um certo sentido, a relação de uma sociedade com o espaço e com a natureza,
em outras palavras, com a paisagem de seu ecúmeno. (BERQUE, 1984, apud HOLZER,
2004, p. 57).

Nesta relação proposta por Berque acontece uma dialética marca-matriz na formulação do conceito de paisagem. Por contar com a matéria necessária para o processo de produção, existe um sentido funcional, e por se inscrever no imaginário social, constituindo-se em um fator simbolizante de segurança e continuidade, a paisagem demonstra o sentido ao simbólico (CORRÊA, 2012). Corrêa (2012), ainda coloca a modernização e industrialização do rural e do urbano como exemplos de rompimento da estabilidade social e transformação da paisagem, uma vez que esta mudança, ao percorrer o tempo, envolve complexidades, tensões e negociações entre diferentes agentes sociais, que acabam reconstruindo a paisagem segundo seus próprios interesses, afetando as marcas e matrizes. Todavia, esta mudança não acontece de maneira igual no rural e no urbano.

O quarto grupo definido por Corrêa (2012), se refere à "paisagem da simulação”, este tipo de paisagem agrupa os ambientes construídos com a intenção de criar diferentes representações e estruturas daquelas já existentes em determinado lugar. "Trata-se de paisagens espacial e temporalmente descontextualizadas, construídas recentemente com a intenção de lucros. Estas paisagens reproduzem atividades e formas de outros lugares e tempos, criando um deslocamento espaço-temporal" (p. 38). Em uma escala global, o autor destaca como exemplo o movimento de colonização e disputa territorial que acontece na América Latina e, em uma escala nacional, a 
mudança da paisagem no centro de Blumenau, cidade brasileira do estado de Santa Catarina que implantou uma política que obriga as construções do centro da cidade serem no estilo bávaro, criando uma germanização da paisagem (CORRÊA, 2012).

Por último, destaca-se o grupo denominado de "paisagem e literatura". De acordo com Corrêa (2012), esse interesse da geografia cultural em criar análises a partir da relação paisagem e literatura é recente e se fortaleceu como possibilidade de estudo a partir de 1970. O autor interpreta que este interesse acontece "quando a paisagem, ou o espaço, torna-se parte integrante da trama e não apenas um necessário pano de fundo" (p. 39). Nesse sentido, o trabalho de Rocha (2011) é um exemplo. A autora analisa os principais autores que fizeram do cacau personagem principal de suas obras. Para ela "o uso da literatura nos trabalhos geográficos permite avaliar a originalidade e a personalidade dos lugares e fornece exemplos de apreciação pessoal das paisagens” (p. 18).

Esta formulação proposta por Corrêa (2012) nos proporciona uma compreensão inicial sobre a direção dos estudos da geografia cultural que voltaram a considerar a paisagem pós-1970. Segundo Luchiari (2001), a geografia cultural vê a paisagem como expressão material do significado que a sociedade oferece ao meio, relacionando-se com a cultura. É nesse sentido que se torna necessária a ação do geógrafo que se preocupa com as culturas, pois "ao descrever a paisagem, exerce suas observações na busca de decodificar seus elementos simbólicos e continuadamente tirando conclusões e estabelecendo relações com os materiais visíveis na paisagem" (ROSENDAHL, 2012, p. 49). Essa decodificação, essa análise acerca da paisagem e dos aspectos culturais é realizada a partir de estudos teóricos e práticos que a ciência geográfica e, particularmente, a geografia cultural nos proporciona (Tabela 1).

Percorrendo as leituras sobre estes novos caminhos desta vertente do pensamento geográfico, percebemos, cada vez mais, aproximações com outras áreas das humanidades. Além disso, podemos perceber que o conceito de paisagem se torna um elo importante entre a geografia, as culturas e os diferentes conhecimentos científicos.

Tabela 1: Entendimentos do conceito de paisagem na geografia cultural.

\begin{tabular}{|c|c|}
\hline GEOGRAFIA TRADICIONAL & NOVA GEOGRAFIA CULTURAL \\
\hline $\begin{array}{l}\text { - Conceito descritivo; } \\
\text { - Investigação objetiva através dos elementos fixos } \\
\text { (naturais) e móveis (antrópicos); }\end{array}$ & $\begin{array}{l}\text { - Conceito fluido; } \\
\text { - Investigação dos aspectos objetivos e subjetivos } \\
\text { presentes nas culturas; }\end{array}$ \\
\hline - Compreensão a partir do visível; & - Compreensão a partir dos diferentes sentidos; \\
\hline $\begin{array}{l}\text { - A materialidade é mais relevante que a } \\
\text { imaterialidade; }\end{array}$ & $\begin{array}{l}\text { - A imaterialidade é tão relevante quanto a } \\
\text { materialidade; }\end{array}$ \\
\hline - Objeto de estudo da Geografia. & - Categoria de estudo da Geografia. \\
\hline
\end{tabular}




\section{CONSIDERAÇÕES FINAIS}

Levando em consideração os aspectos abordados viu-se neste trabalho que os estudos relacionados à geografia cultural passaram por etapas de consolidação, na geografia tradicional, desde o século XIX tendo destaque na Alemanha, França e Estados Unidos com relevantes obras de importantes geógrafos como Friedrich Ratzel, Paul Vidal de La Blache e Carl Sauer. Contudo, a essência da geografia cultural não era trabalhada inicialmente, apenas sua descrição e o interesse nos objetos materiais e técnicas que possuíam evidência. O conceito de paisagem era compreendido no âmbito do estático, relacionado à fisionomia da área e não conciliado a subjetividade, pois as concepções deterministas e possibilistas possuíam grande influência na interpretação deste conceito de estudo geográfico.

A partir da segunda metade do século XX, com as transformações históricas, políticas, sociais e culturais, a geografia cultural passa a reformular seu campo de estudo. A necessidade de compreender e analisar o espaço além da descrição e quantificação ganhava sentido, e assim as investigações sobre a dimensão cultural e histórica das ações humanas imbricadas no espaço ganhavam visibilidade, tanto a materialidade quanto a imaterialidade contribuíram para a análise dos fenômenos culturais que variam através do espaço, seja através da arte, religião, linguagem, crença, economia e trabalho.

O objetivo proposto de realizar uma reflexão sobre a trajetória dos estudos culturais na Geografia, destaca o pressuposto sobre seu papel dentro da ciência geográfica, que evidencia a intencionalidade na percepção do espaço através da experiência humana, cultural e individual. Reafirmando que a temática cultural e seus estudos inseridos na academia ampliaram e consolidaram o potencial de contribuições no âmbito teórico-conceitual, principalmente vinculada à relação natureza e sociedade, contribuindo para o entendimento e visibilidade da relação cultura, diversidade, símbolos e identidade.

\section{REFERÊNCIAS}

AMORIM FILHO, O. B. A evolução do pensamento geográfico e a fenomenologia. Sociedade \& Natureza, v. 11, n. 21/22, p. 67-87, 2014.

BESSE, J. M. Ver a Terra. Seis ensaios sobre a paisagem e a geografia. São Paulo: Perspectiva, 2014. 120p.

BUTTIMER, A. Apreendendo o dinamismo do mundo vivido. In: CHRISTOFOLETTI, A. (Org.). Perspectivas da geografia. São Paulo: DIFEL, 1985. cap. 8, p. 165-193.

CLAVAL, P. As abordagens da Geografia Cultural. In: CASTRO, I. E. (Orgs.). Explorações Geográficas - percursos no fim do século. Rio de Janeiro: Bertrand Brasil, 1997. cap. 3, p. 89-117. 
CLAVAL, P. O papel da nova geografia cultural na compreensão da ação humana. In: ROSENDAHL, Z; CORREAA, R. L. (Orgs). Matrizes da Geografia Cultural. Rio de Janeiro: Ed. UERJ, 2001. p. 35-86.

CLAVAL, P. “A volta do cultural” na geografia. Mercator, Fortaleza, v. 1, n. 1, p. 19-28, 2009.

CLAVAL, P. A paisagem dos geógrafos. In: CORREAA, R. L.; ROSENDAHL, Z. (Orgs.). Paisagens, textos e identidade. Rio de Janeiro: Ed. UERJ, 2004. cap. 1, p. 13-74.

CLAVAL, P. A geografia cultural. 3. ed. Florianopolis: Ed. UFSC, 2007. 453p.

CLAVAL, P. A contribuição francesa ao desenvolvimento da abordagem cultural na geografia. In: CORREAA, R. L.; ROSENDAHL, Z. (Orgs.). Introdução à geografia cultural. Rio de Janeiro: Bertrand Brasil, 2007. p.147-166.

CLAVAL, P. Epistemologia da Geografia. Florianópolis: Editora UFSC, 2011. 407p.

CORREAA, R. L. Sobre a geografia cultural. 2009. Disponível em: https://ihgrgs.org.br/. Acesso em: 24 jun. 2021.

CORRÊA, R. L. Carl Sauer e a escola de Berkeley - uma apreciação. In: ROSENDAHL, Z.; CORREAA, R. L. (Orgs). Matrizes da Geografia Cultural. Rio de Janeiro: Ed. UERJ, 2001. p. 9-34.

CORRÊA, R. L. Paisagem e Geografia. In: ALVES, I.; LEMOS, M.; NEGREIROS, C. (Orgs.). Literatura e Paisagem em Diálogo. Rio de Janeiro: Edições Makunaíma, 2012. cap. 2, p. 29-43.

CORREAA, R. L. Carl Sauer e Denis Cosgrove: a paisagem e o passado. Espaço Aberto, Rio de Janeiro, v. 4, n. 1, p. 37-46, 2014.

CORREAA, R. L. Denis Cosgrove: a paisagem e as imagens. Espaço e Cultura, Rio de Janeiro, n. 29, p. 7-21, 2011.

COSGROVE, D. A geografia está em toda parte: cultura e simbolismo nas paisagens humanas. In: CORRÊA, R. L.; ROSENDAHL, Z. (Orgs.). Geografia cultural: uma antologia. v. 1. Rio de Janeiro: Ed. UERJ, 2012. cap. 12, p. 219-237.

DUNCAN, J. S. O Supra-orgânico na Geografia Cultural Americana. In: CORRÊA, R. L.; ROSENDAHL, Z. (Orgs.). Introdução à Geografia Cultural. Rio de Janeiro: Bertrand Brasil, 2003.

FURLANETTO, B. H.; KOZEL, S. Paisagem cultural: da cena visível à encenação da alma. Ateliê Geográfico, v. 8, n. 3, p. 215-232, 2014.

HOLZER, W. Augustin Berque: um trajeto pela paisagem. Espaço e Cultura, Rio de Janeiro, n. 1718, p. 17-18, 2004.

HOLZER, W. A Geografia Humanista: Uma revisão. Espaço e Cultura, Rio de Janeiro, p. 137-147, 2013.

LA BLACHE, P. V. Os gêneros de vida na geografia humana. In: HAESBAERT, R.; PEREIRA, S. N.; RIBEIRO, G. Vidal, Vidais: textos de geografia humana, regional e política. Rio de Janeiro: Bertrand Brasil, 2012. p.131-158. 
LÉVY, J. Qual o sentido da Geografia Cultural?. Revista do Instituto de Estudos Brasileiros, São Paulo, n. 61, p. 19-38, 2015.

LOWENTHAL, D. Geografia, experiência e imaginação: Em direção a uma epistemologia geográfica. In: CHRISTOFOLETTI, A. (Org.). Perspectivas da Geografia. São Paulo: DIFEL, 1985. cap. 6, p. 103-141.

LUCHIARI, M. T. A (re)significação da paisagem no período contemporâneo. In: ROSENDAHL, Z.; CORRÊA, R. L (Orgs.). Paisagem, Imaginário e Espaço. Rio de Janeiro: Ed. UERJ, 2001. p. 928.

MATHEWSON, K.; SEEMANN, J. A geografia histórico-cultural da Escola de Berkeley: um precursor ao surgimento da História Ambiental. Varia hist., Belo Horizonte, v. 24, n. 39, p. 71-85, 2008.

MEINIG, D. W. O olho que observa: dez versões da mesma cena. Espaço e Cultura, Rio de Janeiro, n. 13, p. 35-46, 2002.

NAME, L. O conceito de paisagem na geografia e sua relação com o conceito de cultura. GeoTextos, Salvador, v. 6, n. 2, p.163-186, 2010.

RATZEL, F. Geografia do homem (Antropogeografia). In: MORAES, A. C. R. Ratzel. São Paulo: Ática, 1990.

RELPH, E. Reflexões sobre a emergência, aspectos e essência de lugar. In: MARANDOLA, E.; HOLZER, W.; OLIVEIRA, L. (Orgs.). Qual o espaço do lugar? São Paulo: Perspectiva, 2014. p. 17-32.

ROCHA, L. B. O cacau na literatura regional do sul da Bahia: ícone de diferenças socioespaciais. Geograficidade, Rio de Janeiro, v. 1, n. 1, p. 16-31, 2011.

ROSENDAHL, Z. Paisagem simbólica como descrição da personalidade do lugar: a certidão de nascimento do Brasil. In: ALVES, I.; LEMOS, M.; NEGREIROS, C. (Orgs.). Literatura e Paisagem em diálogo. Rio de Janeiro: Edições Makunaima, 2012. cap. 3, p. 45-56.

SALGUEIRO, T. B. Paisagem e geografia. Revista Finisterra, Lisboa, v. 36, n. 72, p. 37-53, 2001.

SAUER, C. O. A morfologia da paisagem. In: Paisagem, Tempo e Cultura. CORRÊA, R. L.; ROSENDAHL, Z. (Orgs.). Rio de Janeiro: EDUERJ, 1998 (1925).

SCHIER, R. A. Trajetórias do conceito de paisagem na geografia. Raega - O Espaço Geográfico em Análise, Curitiba, n. 7, p. 79-85, 2003.

SPETH, W. Historicismo: a visão disciplinaria de mundo de Carl Sauer. In: CORRÊA, R. L.; ROSENDAHL, Z. (Orgs.). Sobre Carl Sauer. Rio de Janeiro: Ed. UERJ, 2011.

TUAN, Y. F. Geografia Humanística. In: CRHISTOFOLETTI, A. (Org.). Perspectivas da geografia. São Paulo: DIFEL, 1985. cap. 7, p.143-164.

VALCÁRCEL, J. O. Los horizontes de la geografia: teoria de la Geografia. Barcelona: Ariel, 2000. 608p. 
WILLIAMS, R. Base e superestrutura na teoria cultural marxista. Espaço e Cultura, Rio de Janeiro, n. 14, p. 7-21, 2002.

ZANATA, B. A. A abordagem cultural na geografia. Transpori(ação), v. 9, n. 1, p. 224-235, 2008. 